\section{Morphological studies on the seasonal changes in the epididymal duct of the one-humped camel (camelus dromedarius)}

\author{
Ahmed El-Zuhry Zayed, \\ Khaled Aly, Ismail Abdel-Aziz Ibrahim, \\ Fatma Mohammed Abd El-maksoud \\ Department of Anatomy and Histology, \\ Faculty of Veterinary Medicine, Assiut \\ University, Assiut, Egypt
}

\section{Abstract}

The present work was carried out on 20 testes and epididymis of sexually mature camels to elucidate the gross anatomical, morphometerical, light microscopical and scanning electron microscopical features of the epididymis in different seasons. Anatomically, the epididymal duct of a camel consists of three parts head, body and tail. Histomorphologically, the epididymal duct is subdivided into initial, middle and terminal segments, of which the middle segment is further subdivided into proximal, intermediate and distal parts. There is a gradual decrease in the epithelial height of the epididymal duct from the initial to the terminal segments. This mechanically facilities passage of the sperms toward the terminal segment. High epithelium in the initial segment may indicate a more absorptive power of the epithelium in this segment. The seasonal reproductivety of the epididymal duct in the camel expressed by variations in the weight and volume of the epididymis, total diameter of the epididymal duct, epithelial height, length of the stereocilia, thickness of the muscular coat and cellular distributions in different segments. The spring months offer ideal circumstances for maximal reproductive activity in this species. The cellular components of the epididymal duct epithelium of the camel displays important morphological changes from season to another showing signs of increasing activity during spring in comparison to decreasing activity in other seasons. PAS positive granules are demonstrated in different segments of the epididymal duct and intraepithelial glands in different seasons. These granules are relatively more numerous in spring. The lamina propria surrounding the epididymal duct contains a layer of the elastic fibers which is very thick in winter, thick in spring and thin in other seasons. This increase in thickness of the elastic fibers predisposes for the increase in the total diameter of the epididymal duct in spring. It was conclude that the muscular coat of the middle and terminal segments is the thickest in spring that may be helpful for powerful ejaculation.

\section{Introduction}

The camel is an important livestock species used for transport of people in desert and semi desert areas. ${ }^{1}$ Nowadays a new role was created for the camel as milk, meat, wool, hair and hides production. ${ }^{2}$ This drawn attention to the need for efficient reproduction. ${ }^{3}$

The reproductive efficiency in camel varies with the season of the year. Camels are considered seasonal breeders. The seasonal variations are influenced by geographic locations, availability of food and climatic conditions. ${ }^{4}$ The rutting season has been reported to occur during spring in Egypt. ${ }^{5}$ The breeding season has been reported from March to August in Sudan $^{6}$ and from November to February in India. ${ }^{7}$

The epididymis is a dynamic organ that controls not only the maturation spermatozoa but also their exit from the male reproductive system and it acts as a storage reservoir for spermatozoa. ${ }^{8}$ The current study aims to elucidate the morphometrical and morphological changes in the epididymis of the camel in Upper Egypt (Assiut governorate) in relation to season.

\section{Materials and Methods}

The present work was carried out on 20 testes and epididymes collected from mature clinically healthy camels (Camelus dromedarius) all over the year (5 in every season). The materials were collected from Baniadie slaughter house in Assiut governorate.

The testes and the epididymes were weighed in grams. The epididymis was then carefully dissected from the testis and each was weighed separately. The volume $(\mathrm{mL})$ of both testes and epididymes together and separately were determined by using fluid displacement. The materials were then preserved in $10 \%$ formalin and kept for further description. Using the obtained measurements, some relative calculations were made, and all were listed in tables.

For Scanning Electron Microscopy, small pieces were taken from the three segments of the epididymal duct namely initial, middle and terminal segments, fixed in mixture of paraformaldehyde solution (2.5\%) and gluteraldehyde solution (2.5\%) in phosphate buffer (pH 7.3) for 24 hours. The samples were washed in $0.1 \mathrm{M}$ phosphate buffer, dehydrated
Correspondence: Khaled Aly, Department of Anatomy \& Histology, Faculty of Veterinary Medicine, Assiut University, Assiut, Egypt.

E-mail: khaledali69@hotmail.com

Key words: sesonal variation, camel, epidydemis.

Received for publication: 27 November 2011.

Revision received: 1 January 2012.

Accepted for publication: 12 January 2012.

This work is licensed under a Creative Commons Attribution NonCommercial 3.0 License (CC BYNC 3.0).

(C) Copyright A. El-Zuhry Zayed et al., 2012 Licensee PAGEPress srl, Italy

Veterinary Science Development 2012; 2:e3 doi:10.4081/vsd.2012.e3

in graded ethanol, critical point-dried in liquid carbon dioxide, and then coated with gold palladius in a sputtering device. The samples were then examined and photographed using JSM-5400LV scanning electron microscope operated at $20 \mathrm{KV}$ in the EM center of Assiut University.

For Light Microscopy, the epididymal duct (immediately obtained after slaughtering) were divided into segments according to Tingari and Moniem. ${ }^{9}$

Small pieces were taken from the different segments, fixed in two kinds of fixatives namely, Bouin's solution 10 and $10 \%$ of neutral buffered formalin. After proper fixation, the specimens were dehydrated in graded ethanol, cleared in xylene, embedded in paraplast and sectioned at 3-5 $\mu \mathrm{m}$ thick sections.

Sections were stained with Haematoxylin and Eosin staining 11 for demonstration of the general histological structure of the examined epididymis PAS reaction 12 for demonstration of neutral mucopolysaccharides; Alcian blue 8GX (pH 2.5) and (pH 1.0) after Steedman,13 for detection of acidic mucopolysaccharides; Crossmon's Trichrome ${ }^{14}$ for detection of muscles and collagenous fibers and Weigert's resorcin fuchsin 15 for detection of elastic fibers.

For Epon-araldite Embedding, small tissue blocks were taken from initial, middle and terminal segments of the epididymis fixed in paraformaldehyde-gluteraraldehyde solution in phosphate buffer.16 Specimens were post fixed in $1 \%$ osmium tetraoxide for one hour, washed in $0.1 \mathrm{M}$ phosphate buffer $(7.3 \mathrm{pH})$, then dehydrated in graded ethanol and embedded in epon-araldite mixture. ${ }^{17}$ Semithin sections $(1 \mu \mathrm{m})$ were cut, stained with Toluidine blue. ${ }^{18}$ All sections were examined with light microscope and photographed.

Some morphometric measurements were made using an image analysis system (Leica 
Q500). These measurements included: the total diameter of the epididymal duct in typical cross sections (including basement membrane). In addition, epithelial height and length of the cilia were also measured. Moreover, the thickness of smooth muscle layer surrounding the epididymal duct (muscular coat) were also measured. All obtained data (mean \pm standard deviation) were listed in tables and tested for significance (ANOVA) whenever necessary.

\section{Results}

\section{Gross anatomical features}

The epididymis consists of a highly convoluted duct which is tightly packed in a thick tunica albuginea. Anatomically, the epididymis is composed of three distinct parts: the head, body and tail. It is attached to the head extremity of the testis by a fibrous band. At the area of contact between the medial part of the head and the head extremity of the testis, the efferent ductules pierce the tunica albuginea of the testis, then that of the epididymis to reach the initial part of the epididymal duct.

The weight of the epididymis varies from one season to another recording the highest value in spring followed by autumn, winter and summer. However, the relative weight of the epididymis to the total weight of the testis and epididymis together is high in winter (22.6\%) followed by spring (21.2\%) and summer $(19.2 \%)$. But the lowest value is recorded in autumn (17.6\%) (Table 1 and Table 2).

\section{Scanning electron microscopy}

In cut sections, the epididymal duct is lined by long pseudostratified columnar epithelium arranged in the form of wheat stems (Figure 1A) shows variably sized vacuoles. The luminal surface of these cells is ciliated. Sometimes, numerous bleb like protrusions and rounded secretory vesicles are demonstrated in between and covering the stereocilia.

In spring, the bleb like protrusions and secretory vesicles are frequently observed in the terminal segment (Figure 1B). But in autumn they are observed in the initial segment (Figure 2). The lumen of the epididymal duct shows collections of sperms in different segments and seasons. In spring, these collections are mainly seen in the middle segment. However in other seasons the sperms are mostly seen sticking to the luminal surface of the epithelium between the stereocilia particularly in summer and autumn (Figure 3). At low magnifications, the epididymal duct shows the widest lumen and surrounded by a thicker circularly arranged smooth muscle fibers in spring as compared to other seasons (Figure
4). Scanning electron microscopy of the camel spermatozoa demonstrated healthy normally looking spermatozoa in spring (Figure 5). But in other seasons, spermatozoa are smaller in size and more or less abnormally looking.

\section{Light microscopy}

The epididymal duct of the camel is divided into initial, middle and terminal segments. In addition, the middle segment is further subdivided into proximal, intermediate and distal parts. In general, the widest diameter of the epididymal duct is observed in the terminal segment (Table 3, Figure 6). The epididymal duct is lined by a pseudostratified ciliated columnar epithelium and surrounded by thin lamina propria and a circular smooth muscular layer (muscular coat). The height of the epithelium varies between the different segments of the epididymis; the highest epitheli- um is seen in the initial segment and decreases gradually toward the terminal segment (Table 4, Figure 7). The epithelium consists of five cell populations: principal, basal, apical, dark and halo cells.

The epididymis of the camel shows moderate seasonal differences, which are expressed by variations in the total diameter of the duct, epithelial height, length of the stereocilia, luminal diameter, thickness of muscular coat and the cellular distribution.

The total diameter of the epididymal duct shows variations between different segments of the epididymal duct in different seasons (Table 3, Figure 6). It decreases gradually from initial segment to the intermediate part of the middle segment then increases gradually in the distal part of the middle segment until reaching the maximum diameter in the terminal segment (Figure 8 and Figure 9). The

Table 1. The weight of the testis and epididymis in different seasons of the year.

\begin{tabular}{lccc} 
Seasons & Testis & Epididymis & \% epididymis /testis+epididymis \\
Spring & $99.93 \pm 22.47$ & $26.83 \pm 2.21$ & $21.16 \%$ \\
Summer & $77.80 \pm 25.70$ & $18.50 \pm 5.63$ & $19.21 \%$ \\
\hline Autumn & $88.5 \pm 22.13$ & $18.95 \pm 1.08$ & $17.63 \%$ \\
Winter & $68.68 \pm 14.96$ & $18.82 \pm 1.15$ & $22.60 \%$ \\
\hline
\end{tabular}

Table 2. The volume of testis and epididymis $(\mathrm{cm} 3)$ in different seasons of the year.

\begin{tabular}{lccc} 
Seasons & Testis & Epididymis & \% epididymis /testis+epididymis \\
Spring & $97.83 \pm 21.78$ & $25.66 \pm 4.96$ & $20.77 \%$ \\
Summer & $77.33 \pm 24.01$ & $18.33 \pm 5.03$ & $19.17 \%$ \\
\hline Autumn & $85.75 \pm 20.46$ & $21.25 \pm 2.50$ & $19.80 \%$ \\
Winter & $71.80 \pm 16.17$ & $19.80 \pm 0.40$ & $22.90 \%$ \\
\hline
\end{tabular}

Table 3. Total diameter $(\mu \mathrm{m})$ of different segments of the epididymal duct in different seasons of the year.

\begin{tabular}{lcccc} 
Seasons & Spring & Summer & Autumn & Winter \\
IS & $279.73 \pm 19.60^{\mathrm{a}}$ & $298.5 \pm 10.70^{\mathrm{a}}$ & $301.01 \pm 22.90^{\mathrm{a}}$ & $293.41 \pm 3.43^{\mathrm{a}}$ \\
MS(P) & $285.4 \pm 4.42^{\mathrm{a}}$ & $276.12 \pm 7.86^{\mathrm{a}}$ & $273.26 \pm 11.30 \mathrm{a}$ & $231.51 \pm 10.71^{\mathrm{b}}$ \\
\hline MS(I) & $290.31 \pm 14.50^{\mathrm{a}}$ & $221.4 \pm 7.86^{\mathrm{bc}}$ & $234.26 \pm 3.39 \mathrm{~b}$ & $207.08 \pm 10.80 \mathrm{c}$ \\
MS(D) & $352.34 \pm 16.10^{\mathrm{a}}$ & $262.83 \pm 6.97 \mathrm{~b}$ & $248.64 \pm 19.41^{\mathrm{b}}$ & $250.06 \pm 7.65^{\mathrm{b}}$ \\
\hline TS & $392.05 \pm 22.41^{\mathrm{a}}$ & $328.52 \pm 10.1 \mathrm{c}^{\mathrm{c}}$ & $363.7 \pm 14.63^{\mathrm{b}}$ & $373.12 \pm 4.14 \mathrm{ab}$ \\
\hline
\end{tabular}

Means within the same row with different superscripts are significantly different $(\mathrm{P}<0.05)$. IS, (initial segment); MS (P), middle segment (proximal part); MS (I), middle segment (intermediate part); MS (D), middle segment (distal part); TS, terminal segment.

Table 4. Epithelial height $(\mu \mathrm{m})$ of different segments of the epididymal duct in different seasons of the year.

\begin{tabular}{lcccc} 
Seasons & Spring & Summer & Autumn & Winter \\
IS & $76.95 \pm 6.50^{\mathrm{b}}$ & $88.96 \pm 8.28^{\mathrm{ab}}$ & $94.75 \pm 6.70^{\mathrm{a}}$ & $86.19 \pm 4.90^{\mathrm{ab}}$ \\
MS(P) & $51.93 \pm 2.21^{\mathrm{a}}$ & $49.48 \pm 0.96^{\mathrm{a}}$ & $55.29 \pm 4.50^{\mathrm{a}}$ & $55.63 \pm 3.57^{\mathrm{a}}$ \\
\hline MS(I) & $44.18 \pm 2.77^{\mathrm{b}}$ & $47.03 \pm 2.22 \mathrm{a}^{\mathrm{b}}$ & $50.57 \pm 1.45^{\mathrm{a}}$ & $47.02 \pm 2.03^{\mathrm{ab}}$ \\
MS(D) & $53.49 \pm 3.57^{\mathrm{a}}$ & $51.28 \pm 1.64^{\mathrm{a}}$ & $50.53 \pm 2.33^{\mathrm{ab}}$ & $46.15 \pm 2.05^{\mathrm{b}}$ \\
\hline TS & $44.17 \pm 2.03^{\mathrm{a}}$ & $43.32 \pm 1.17 \mathrm{a}$ & $47.06 \pm 3.42^{\mathrm{a}}$ & $46.17 \pm 1.18^{\mathrm{a}}$
\end{tabular}

Means within the same row with different superscripts are significantly different $(\mathrm{P}<0.05)$. IS, (initial segment); MS (P), middle segment (proximal part); MS (I), middle segment (intermediate part); MS (D), middle segment (distal part); TS, terminal segment. 
above is observed in all seasons except in spring where the diameter of the duct increases gradually from the initial segment toward the terminal segment (Figure 10).

On the other hand, the height of the epithelium decreases toward the terminal segment of the epididymal duct. Generally the highest epithelium is demonstrated in autumn followed by winter, summer and the lowest epithelium is seen in spring (Table 4, 7). The longest stereocilia is seen in autumn followed by spring, winter and summer (Table 5). In spring, the luminal diameter increases gradually toward the terminal segment (Figure 10). In spring, the lumina of the intermediate and distal parts of the middle segment are filled with sperms but in summer, autumn and winter the sperms are demonstrated in all parts of the middle segment (Figures 10A and Figure 11). In the terminal segment, the widest lumen is demonstrated in spring (Figure 10B). In the latter segment, the luminal surface of the epididymal epithelium is mostly folded in winter (Figure 12).

The distribution and morphology of various cells constituting the epididymal epithelium shows a moderate seasonal variation.

In all seasons, the principal cells constitute the predominant cells throughout the epididymal duct and display important morphological changes from season to another. In spring, the nuclei of the principal cells in the initial and middle segments are vesicular, oval with few chromatin condensations mainly adherent to the inner surface of the nuclear membrane (Figure 13). Cytoplasmic vacuoles are demonstrated in the middle and terminal segments of the epididymal duct. These cytoplasmic vacuoles are frequently seen in spring and summer (Figure 14). But they are scarce in autumn and winter. In addition, the apical protrusions and vesicles are also demonstrated in the terminal segment (Figure 15). In summer, the nuclei of principal cells are oval with numerous heterochromatin patches. In autumn, they appear condensed, irregular elongated oval with several heterochromatin patches. These cells have large amount of dense bodies around the nucleus in the middle and terminal segments (Figure 16). Small and few vacuoles are also present in supranuclear positions in the principal cells of the middle and terminal segments. In winter, the nuclei start to attain more round form. Numerous dense bodies are observed in middle and terminal segments but fewer than that of the autumn (Figure 17). The nuclei of principal cells of the terminal segment in spring and winter shows very deep narrow indentations (Figure 15).

The basal cells do not exhibit significant quantitative variations between the different seasons. But in winter these cells are slightly frequent in the middle and terminal segments
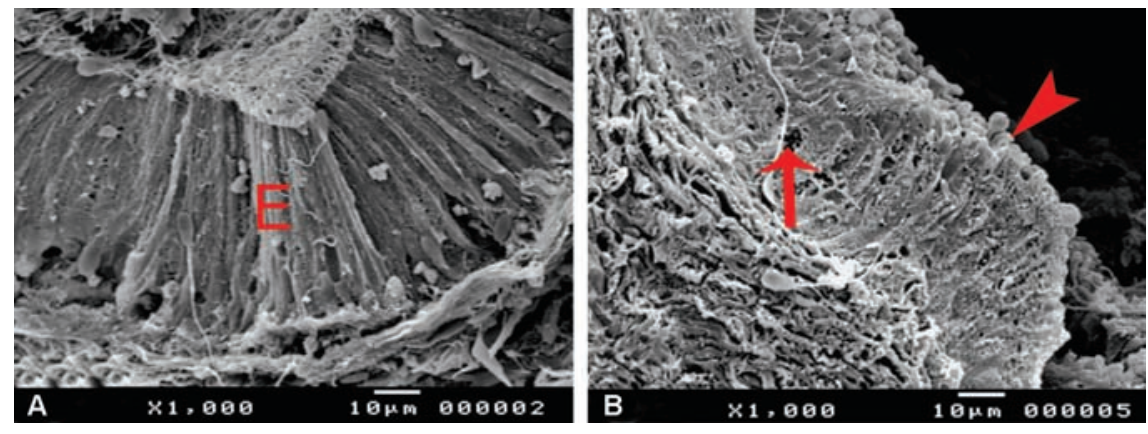

Figure $1 \mathrm{~A}, \mathrm{~B}$. Scanning electron micrographs of the initial and terminal segments of the camel epididymis in spring respectively. The epididymal epithelium $(E)$ is arranged in the form of wheat stuffs and deceases gradually in height distal wards. Notice the presence of the vacuoles (arrow) in the epithelium of terminal segments and apical bleb like protrusions in the terminal segment (arrow head).

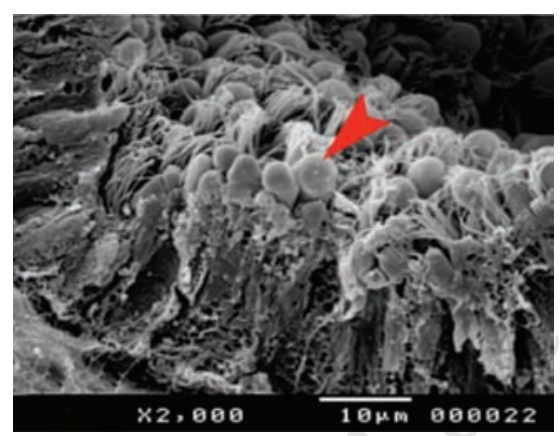

Figure 2. Scanning electron micrograph of the initial segment in autumn showing apical bleb like protrusions (arrow head) amid tufts of cilia.

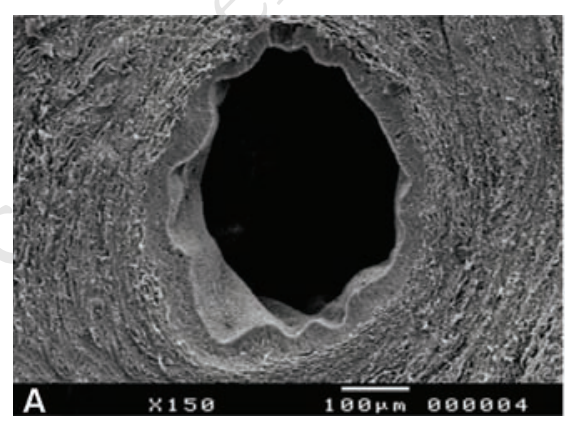

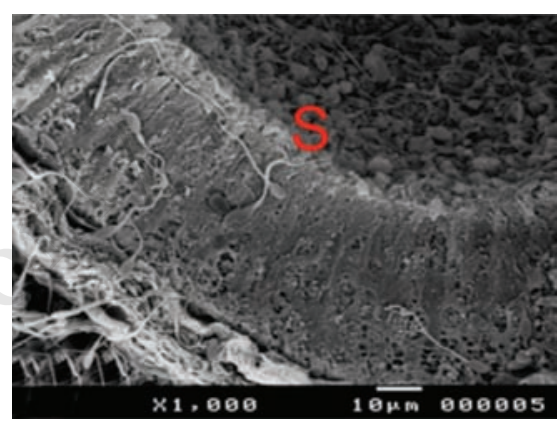

Figure 3. Scanning electron micrographs of the middle segment of the epididymal duct in autumn. Notice that the sperms $(S)$ are sticking to the stereocilia of the epididymal epithelium.

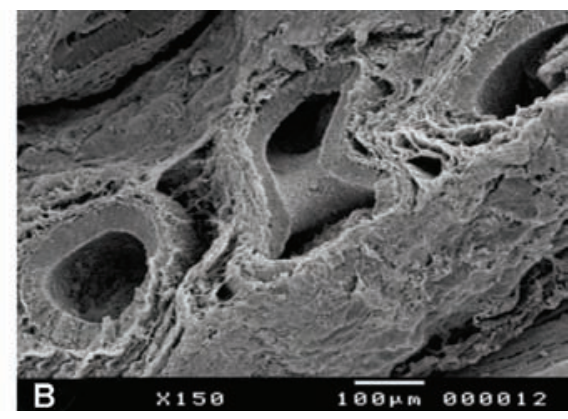

Figure 4 A, B. Scanning electron micrographs showing cut sections of the terminal segment of the epididymal duct in spring and summer. The lumen of the epididymal duct is the widest in spring (A).

(Figure 17). In general, the dark cells increase distalwards the epididymal duct particularly in summer.

In PAS stained sections, the epididymal epithelium shows variable amount of PAS positive granules in different segments and seasons. These granules are relatively more numerous in spring than other seasons. The intraepithelial gland shows also variable PAS positive material. Unlike other seasons most of these glands are almost filled with PAS positive content in spring (Figure 18).

The elastic fibers of the lamina propria show no variations between seasons in the initial and middle segments of the epididymal duct.

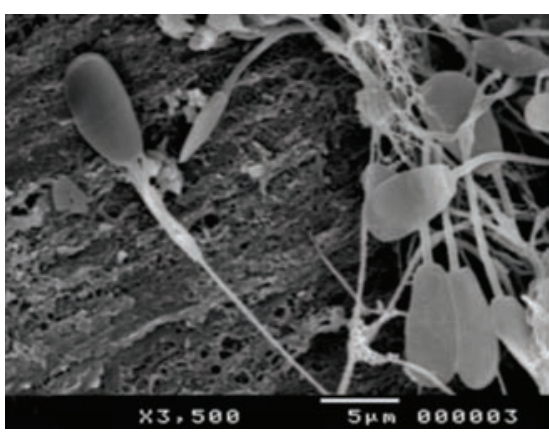

Figure 5. Scanning electron micrographs showing epididymal sperms in spring. Notice that the sperms are healthy and larger in spring. 
But in the terminal segment they are the thickest in spring and winter (Figure 19). The muscular coat shows moderate variations in thickness between different segments of the epididymal duct and between seasons of the year (Table 6, Figure 8).The thinnest muscular coat of the initial segment is demonstrated in spring and the thickest is observed in winter (Figure 20). But the muscular coat of the middle and terminal segments is the thickest in spring (Figure 21). In the terminal segment, the thinnest muscular coat is seen in winter.

\section{Discussion}

The epididymis constitutes an important part of the male genital duct system. It plays key role in the maturation and storage of spermatozoa. 19

Anatomically and in agreement with previous studies ${ }^{9}$ the epididymis of camel consists of three parts i.e. head, body and tail. The whole organ is covered by a thick tunica albuginea which does not allow the epididymal duct to visualize grossly through it. Another reason for the latter statement could be attributed to the narrow epididymal duct as compared to some other domestic animals like bovines..$^{20}$ Where the epididymal duct is about one third more wider than that observed in camel in the present work.

The current study supports the previous findings in different species including camel concerning the gradual decrease in the epithelial height of the epididymal duct from the initial through middle to the terminal segments. $9,20,21,22-24$

This gradual decrease in the epithelial height distal wards the epididymal duct may mechanically facilities passage of the sperms toward the terminal segment. High epithelium in the initial segment may, however indicate a more absorptive power of the epithelium in this segment. In this respect, ${ }^{25}$ reported that in bulls, over $90 \%$ of the fluids entering the epididymal duct is absorbed in the head of the epididymis. In addition, Turner ${ }^{26}$ mentioned that, the removal of fluid is associated with a net resorption of sodium ions between the reta testis and the proximal part of the epididymis in rats. Moreover, and in agreement with previous reports, ${ }^{24,27-30}$ the epididymal epithelium in the initial segment is supported by a complex set of long and branched stereocilia that decrease in length through the middle segment being very short forming brush border in the terminal segment. Well developed cilia in the initial segment increases the surface area facilitating the movement of molecules into and out of the cell. ${ }^{30-31}$ The decrease in the height of stereocilia between the head and the tail of the epididymis could be attributed to the more active absorptive and secretory functions of the head of the epididymis as compared with those of the tail of the epididymis. ${ }^{32}$ Unlike the findings of Alkafafy ${ }^{20}$ that, the stereocilia show distinct staining with Alcian blue, the stereocilia of the camel epididymis in the current study stain positive with PAS and Alcian blue. In this respect, López et al. ${ }^{33}$ have ascribed this staining pattern in equine head of the epididymis to carboxyl group of glycoproteins and/or glycolipids associated sialic acids or sulfate polysaccharides in the stereocilia.

There is a unanimous agreement that the camel experiences moderate seasonal reproductivety. Although all previous studies have consented that the production of spermatozoa continues throughout the year with variable activities, the season of the sexual activity is a controversial matter. In the available literature there are two main prospects, the first emphasized that the rutting season occurs in winter and spring (December to March or even until May) as reported by Bodenheimer, ${ }^{34}$ Charnot, ${ }^{35}$ Shalash, 36 Novoal as well as 0sman and Azab. ${ }^{37}$ The second one ascertained that the rutting season occurs in spring. ${ }^{38-39}$ Osman and $\mathrm{Azab}^{37}$ have mentioned that the seasonal variation observed in the reproductivity and storage capacity of the testis and epididymis have enabled them to conclude that camels rutting in spring may have a higher fertilization rate than those rutting in autumn. The present work aims to describe the morphological and morphometric characteristics of the epi-

Table 5. Length of stereocilia $(\mu \mathrm{m})$ of different segments of the epididymal duct in different seasons of the year.

\begin{tabular}{lcccc} 
Seasons & Spring & Summer & Autumn & Winter \\
IS & $9.43 \pm 1.07 \mathrm{a}$ & $8.46 \pm 0.23^{\mathrm{a}}$ & $10.06 \pm 1.31^{\mathrm{a}}$ & $6.12 \pm 0.76^{\mathrm{b}}$ \\
MS(p) & $8.16 \pm 0.26 \mathrm{ab}$ & $5.79 \pm 0.87 \mathrm{c}$ & $9.24 \pm 0.56^{\mathrm{a}}$ & $7.09 \pm 0.67 \mathrm{~b}$ \\
\hline MS(I) & $7.29 \pm 0.40 \mathrm{ab}$ & $4.62 \pm 0.36^{\mathrm{c}}$ & $8.16 \pm 0.37 \mathrm{a}$ & $6.95 \pm 0.70^{\mathrm{b}}$ \\
MS(D) & $3.616 \pm 0.28^{\mathrm{b}}$ & $2.47 \pm 0.36^{\mathrm{c}}$ & $2.88 \pm 0.54 \mathrm{bc}$ & $4.69 \pm 0.50^{\mathrm{a}}$ \\
\hline TS & $2.69 \pm 0.39 \mathrm{a}$ & $2.72 \pm 0.13^{\mathrm{a}}$ & $3.10 \pm 0.95^{\mathrm{a}}$ & $2.65 \pm 0.40^{\mathrm{a}}$ \\
\hline
\end{tabular}

Means within the same row with different superscripts are significantly different $(\mathrm{P}<0.05)$. IS, (initial segment); MS $(\mathrm{P})$, middle segment (proximal part); MS (I), middle segment (intermediate part); MS (D), middle segment (distal part); TS, terminal segment.

Table 6. Thickness of muscular coat $(\mu \mathrm{m})$ of different segments of the epididymal duct in different seasons of the year.

\begin{tabular}{lcccc} 
Seasons & Spring & Summer & Autumn & Winter \\
IS & $26.5 \pm 1.85^{\mathrm{b}}$ & $32.58 \pm 2.47 \mathrm{a}$ & $26.91 \pm 1.61 \mathrm{~b}$ & $34.25 \pm 1.51^{\mathrm{a}}$ \\
MS(P) & $31.3 \pm 1.64^{\mathrm{a}}$ & $28.87 \pm 1.65^{\mathrm{ab}}$ & $26.91 \pm 1.88^{\mathrm{b}}$ & $28.38 \pm 1.69_{\mathrm{ab}}$ \\
\hline MS(I) & $35.83 \pm 3.52^{\mathrm{a}}$ & $24.91 \pm 2.18^{\mathrm{b}}$ & $25.54 \pm 1.74 \mathrm{~b}$ & $28.80 \pm 0.59 \mathrm{~b}$ \\
MS(D) & $37.50 \pm 2.41^{\mathrm{a}}$ & $28.71 \pm 1.12^{\mathrm{b}}$ & $26.63 \pm 1.85^{\mathrm{b}}$ & $30.87 \pm 3.50^{\mathrm{b}}$ \\
\hline TS & $41.89 \pm 1.96^{\mathrm{a}}$ & $38.37 \pm 2.81 \mathrm{ab}$ & $40.92 \pm 1.50^{\mathrm{ab}}$ & $36.65 \pm 3.55^{\mathrm{b}}$ \\
\hline
\end{tabular}

Means within the same row with different superscripts are significantly different $(\mathrm{P}<0.05)$. IS, (initial segment); MS (P), middle segment (proximal part); MS (I), middle segment (intermediate part); MS (D), middle segment (distal part); TS, terminal segment.

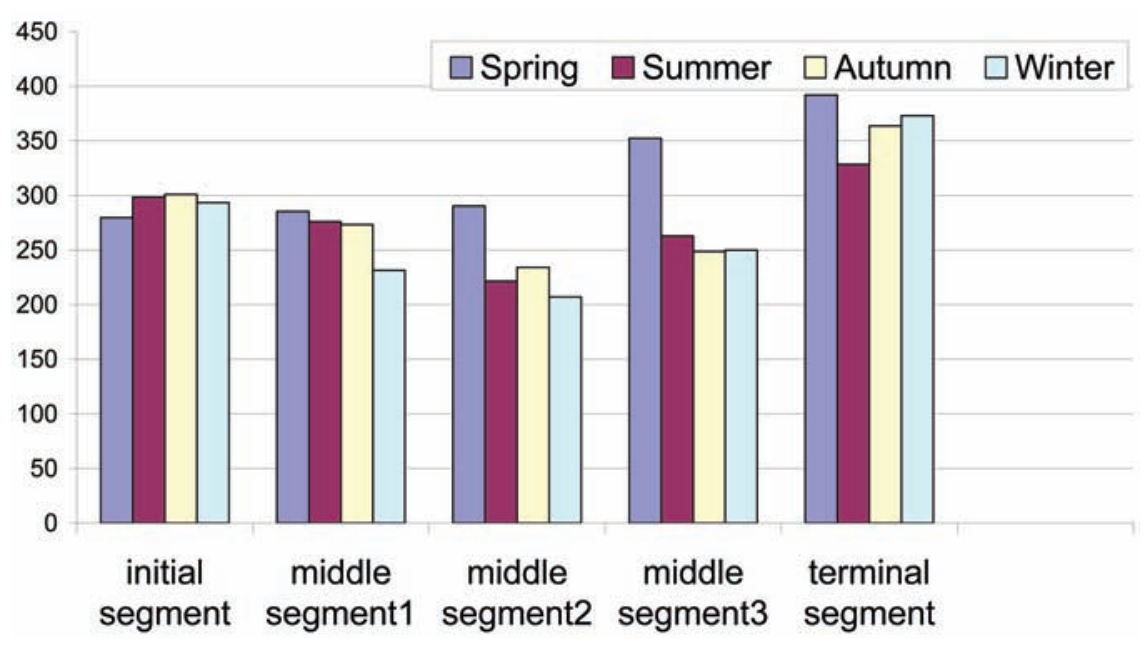

Figure 6. Total diameter $(\mu \mathrm{m})$ of the different segments of the epididymal duct in different seasons of the year. 
didymis of the camel in relation to its annual reproductive cycle. In the current study, the epididymis demonstrates sperms in its lumen in all seasons. However, the morphological, morphometrical and histological characteristics of the epididymis show moderate seasonal differences expressed by variations in the weight and volume of the epididymis, total diameter of the efferent ductules and epididymal duct, epithelial height, length of the stereocilia, thickness of the muscular coat and cellular distributions in different segments. The weight and volume of the epididymis in the current study exhibits moderate seasonal variations where the highest values for both are observed in spring $\left(26.83 \mathrm{~g}\right.$., $25.66 \mathrm{~cm}^{3}$ respectively) and the lowest values are recorded in summer (18.50g., $18.33 \mathrm{~cm}^{3}$ respectively). Ismail (unpublished data) has recorded the highest epididymal weight (16.80 g.) during spring and the lowest (14.54 g.) during autumn. These findings are slightly different from those of Tingari et al. ${ }^{40}$ who mentioned that, maximal testicular weight is attained during the coldest months of the year and that conversely testicular weights are minimal during the hot period. However, Ebada (1994, unpublished data) reported that, the average weight is about $18.3 \mathrm{~g}$. in rutting season (spring and winter) and $14.5 \mathrm{~g}$. in non-rutting season (autumn and summer). In our opinion, the spring months (with increasing day light and temperate temperature) offer ideal circumstances for maximal reproductive activity in this semi domesticated species. In this respect Salisbury et al. ${ }^{41}$ reported that, increasing light in spring when temperatures are not extreme provides the optimum period for fertility. We can also assume that, despite increasing light in summer months, their extreme temperature has a greater negative effect on fertility. Moreover, the improvement in temperature in autumn and winter months is accompanied by short day light which does not give better conditions for increased fertility. A striking finding in the present study is

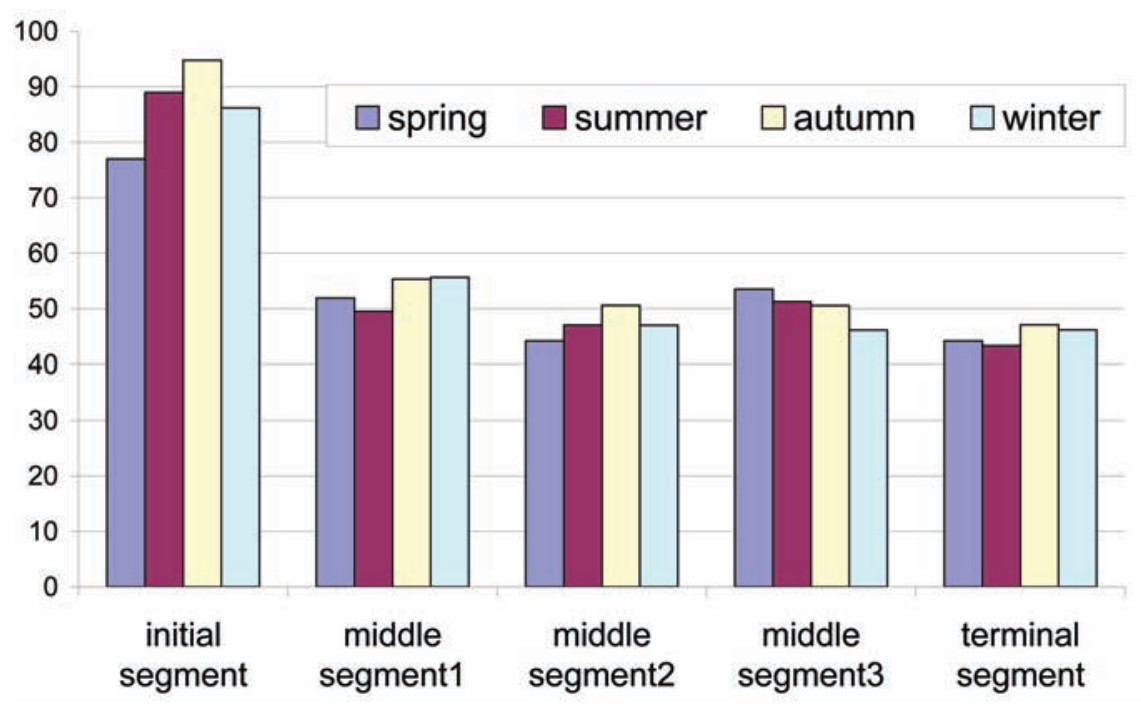

Figure 7. Epithelial height $(\mu \mathrm{m})$ of the different segments of the epididymal duct in different seasons of the year.

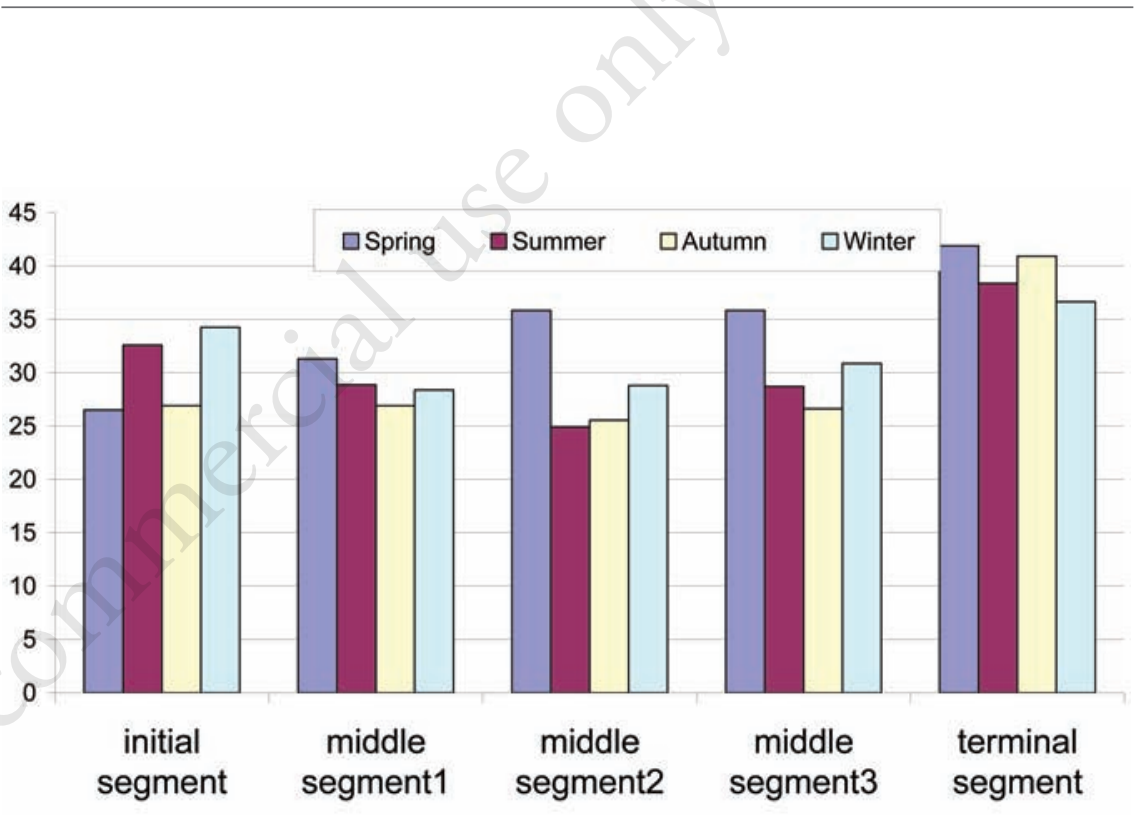

Figure 8. Thickness of muscular coat of the different segments of the epididymal duct in different seasons of the year.
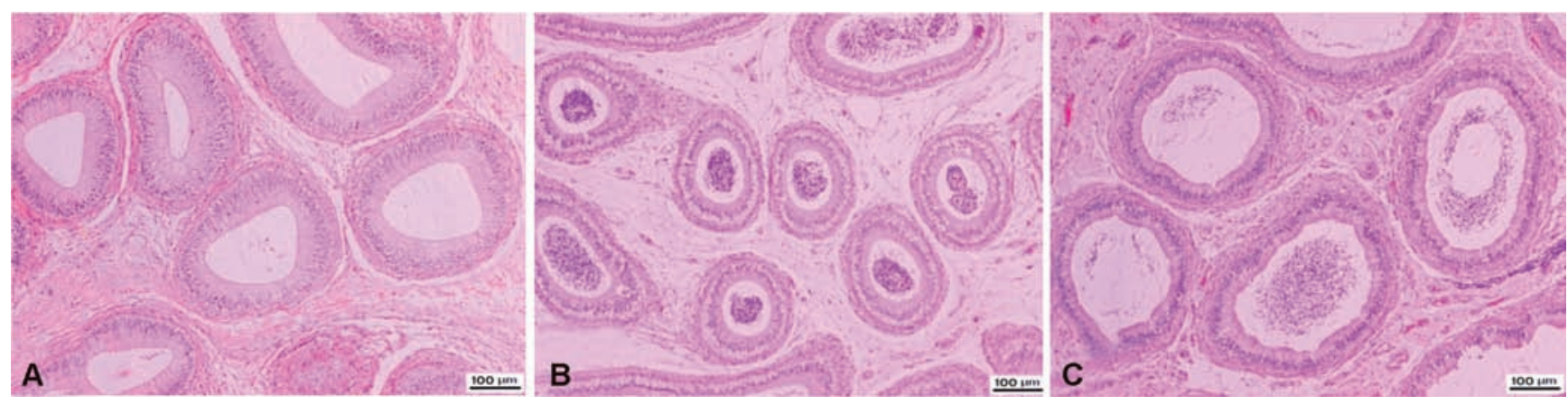

Figure 9 A, B, C. Paraffin sections stained with H\&E showing the epididymal segments in summer. The total diameter of the epididymal duct and the luminal diameter decrease gradually from the initial segment to the intermediate part of the middle segment then increase gradually until reaching the maximum diameter in the terminal segment. Sperms are demonstrated in all parts of the middle segment and the terminal segment. 
noticed when we compare the weight and volume values of the epididymis in different seasons. The weight value is clearly higher than the volume value only in spring. Higher weight value in spring may be attributed to increased intensity of the epididymis due to excessive sperms contents in epididymis.

The total diameter of either efferent ductules or epididymal duct is higher in spring with wider lumen and slightly low lining epithelium as compared to other seasons. Similar findings have been observed by Aguilera-Merlo et al.42-43 in viscacha (typical seasonal breeder) and they have considered such changes as testosterone dependant. The increase in the total and luminal diameter of both efferent ductules and epididymal duct facilities easily passage of the spermatozoa. On the other hand, slightly low epithelium in spring may indicate higher activity, whereas the high epithelium in other seasons may indicate accumulation of secretions within the epithelium and decrease activity. In all seasons except spring, the total diameter of the epididymal duct shows slight narrowing in the two short proximal and intermediate parts of the middle segment before rewidening again in the distal part of the middle segment and terminal segment. This comes in agreement with the results of Tingari and Moniem ${ }^{40}$ and Ebada (1994) in the same species. This narrowing may partly hinder the passage of sperms through the middle segment and this could explain the presence of sperms in all parts of the middle segment in these seasons.

The cellular components of the epididymal epithelium of the camel display important morphological changes from season to another showing signs of increase activity during spring in comparison to decrease activity in other seasons. The principal cells constitute the predominant cells throughout the epididymal duct and they are the most affected cell type in the epididymal epithelium. These cells demonstrate vesicular lightly stained oval nuclei indicating increased activity in comparison to the smaller darkly stained nuclei in other seasons a sign of decreased activity. In addition, the nuclei of the principal cells of the terminal segment in both spring and winter show very deep indentation. This finding comes in agreement with those of Ebada (1994) in the same species which has been interpreted as a sign of highly intense metabolic activity. ${ }^{44}$ Moreover, the frequency of dark cells, which have been considered as a dying cells $^{45}$ increases in summer indicating decreased activity after an active period in spring.

PAS positive granules are demonstrated in efferent ductules and different segments of the epididymal duct in different seasons. However, these granules are relatively more numerous in spring. Moreover, the intraepithelial glands

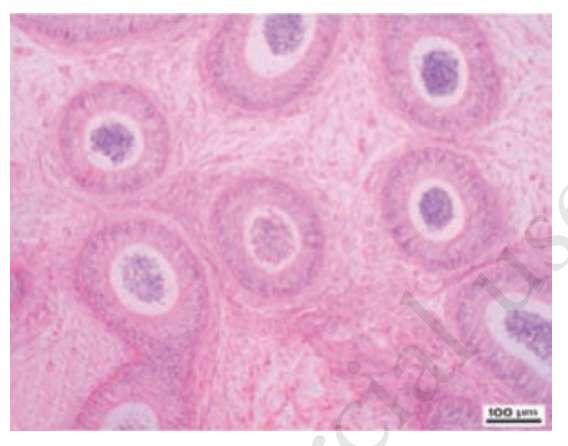

Figure 11. Paraffin section stained with $H \& E$ showing the middle epididymal segments in autumn. Notice the presence of a large mass of the sperms.

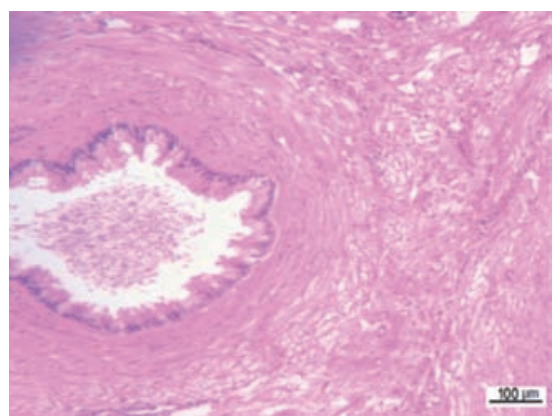

Figure 12. Paraffin sections stained with $H \& E$ showing the terminal epididymal segments in winter. Although sperms are fewer than in autumn, they are seen in almost all epididymal segments. The total diameter of the duct and the luminal diameter is larger than those in autumn particularly in the terminal segments. Notice that the epithelial lining is folded.

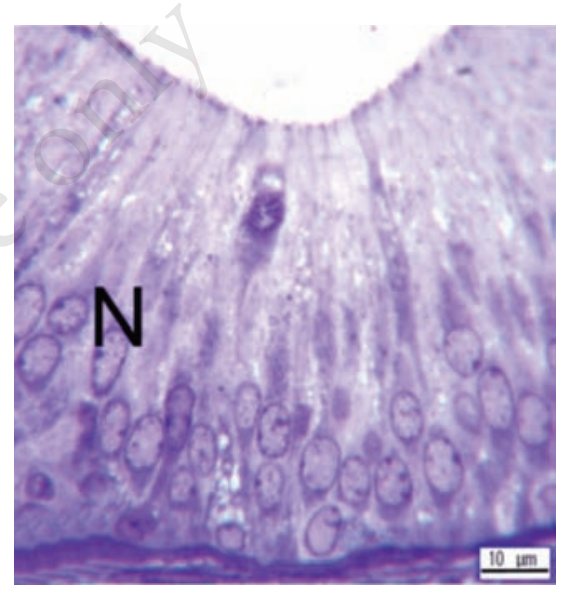

Figure 13. Semithin sections stained with toluidine blue showing the initial segment of the epididymal duct in spring. The nuclei $(\mathrm{N})$ is vesicular with few chromatin condensations.

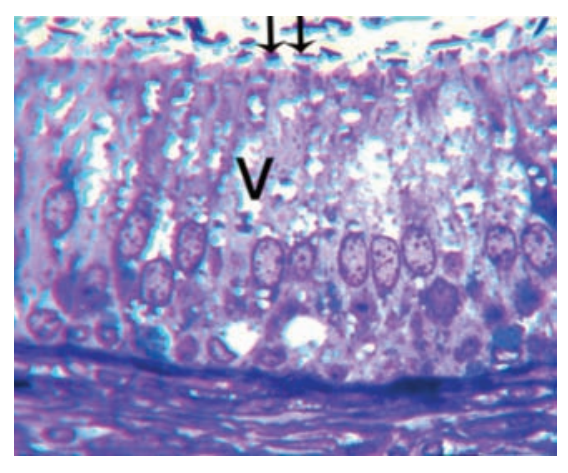

Figure 14. Semithin sections stained with toluidine blue showing the middle segments of the epididymal duct in summer. Numerous cytoplasmic vacuoles are present $(V)$. Notice that the sperms are sticking to the stereocilia (double arrow). 


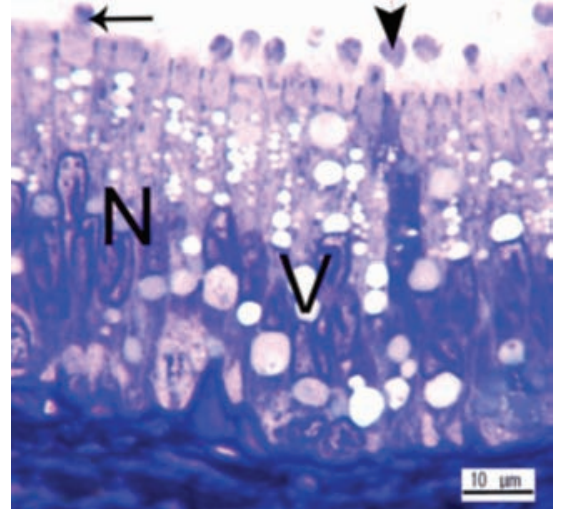

Figure 15. Semithin sections stained with toluidine blue showing the terminal segments of the epididymal duct in spring. The nuclei $(\mathrm{N})$ show very deep indentations. The cytoplasmic vacuoles (V) are demonstratedand also show apical protrusions (arrow) and vesicles (arrow head).

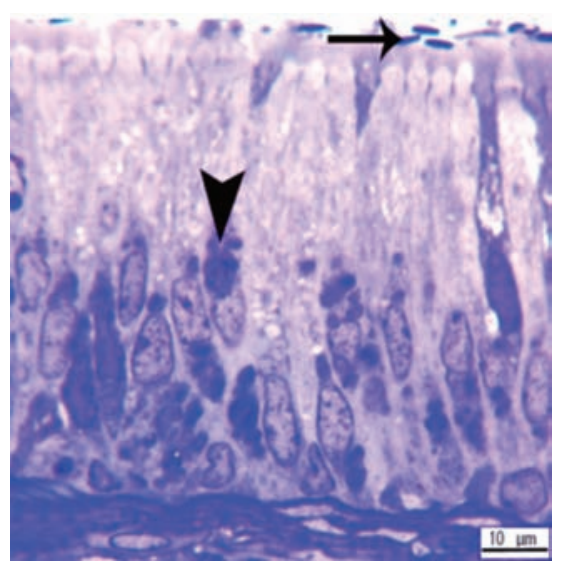

Figure 16. Semithin sections stained with toluidine blue showing the middle segment of the epididymal duct in autumn. The middle segment has large amount of the dense bodies around the nucleus (arrow head). Notice that the sperms are sticking to the stereocilia (arrow).

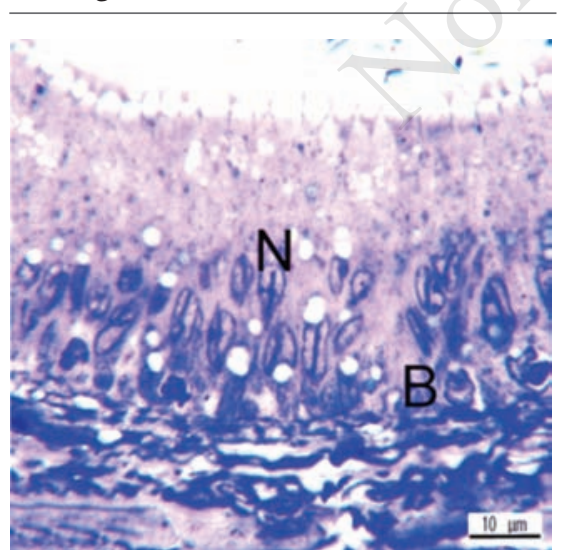

Figure 17. Semithin sections stained with toluidine blue showing the terminal segment of the epididymal duct in winter. The nuclei of the terminal segment $(\mathrm{N})$ show very deep indentations. Notice that the basal cells (B) are slightly frequent in the terminal segments.

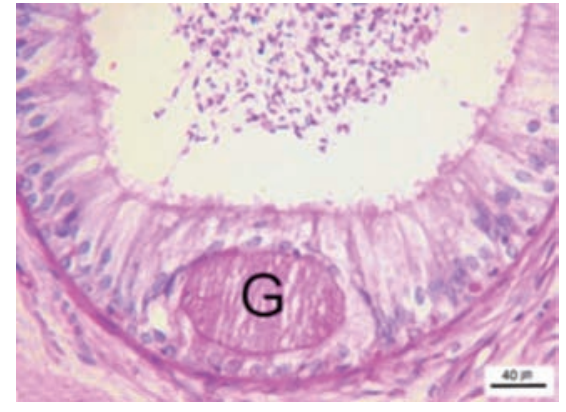

Figure 18. Paraffin sections stained with PAS showing the middle (distal part) of the epididymal duct in sping. Notice that the intraepithelial gland $(G)$ in the distal part of the middle segment show variable amount of PAS positive material, which is massively filling the whole cavity.

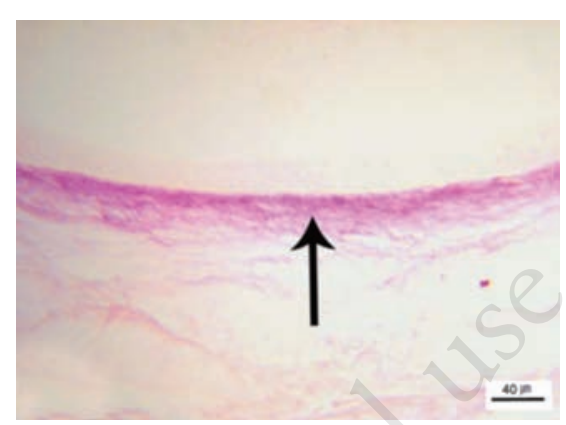

Figure 19. Paraffin sections stained with Weigert's resorcin fuchsin showing terminal segment winter showing thick elastic fibers layer.

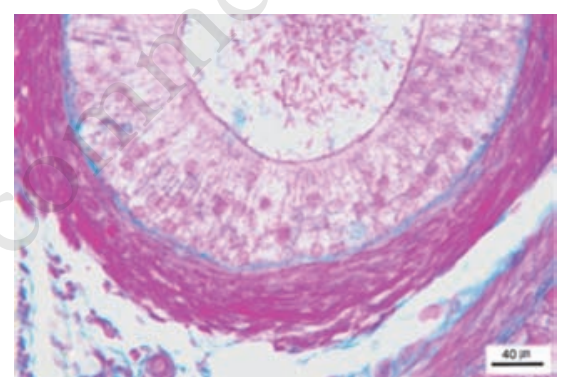

Figure 20. Paraffin sections stained Crossmon's Trichrome showing the distal part of middle segment in spring. The muscular coat are thickest.

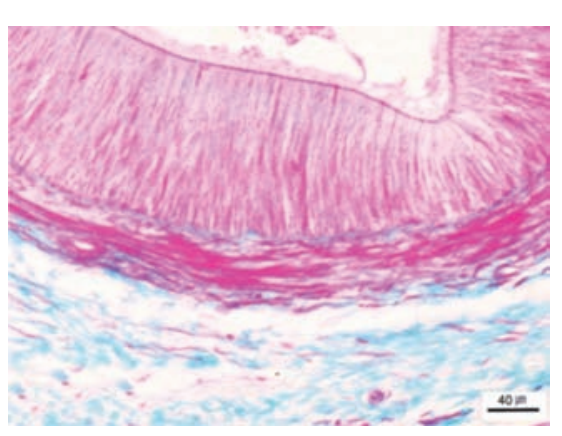

Figure 21. Paraffin sections stained Crossmon's Trichrome showing the initial segment in winter. The muscular coat of the initial segment is thickest in winter. are full of PAS positive material particularly in spring. The PAS positivity gives evidence for the presence of glycoprotein in relation to a secretory product, ${ }^{46}$ which could be an indication of increased activity. ${ }^{24}$ We postulate that, the highest activity is seen in spring which subsides in summer and autumn but starts to build up in winter. In this respect Zayed et al. ${ }^{39}$ have described well developed leydig cells in winter which concede as increased testosterone level in the camel blood during winter (from December to February) as mentioned by Yagil and Etzion. 47

In the current study, basal cells show a relative increase in number during winter. Taking in consideration that these basal cells are thought to be stem cells to the principal cells. ${ }^{48}$ This could be an indication of the above mentioned build up, and may be perquisite for the increase in the total diameter of the epididymal duct in spring. In the same connection, the camel epididymal epithelium shows inward folding during winter, a sign of increased number of lining principal cells that may be needed for expansion of the epididymal diameter in the coming spring.

The epididymal epithelium in the current study displays accumulations of dense bodies in the principal cells in autumn. Abundance of lysosome like dense bodies in the epididymal epithelium may be related to active digestion of sperm and epithelial cells remnants a typical sign of an involuting organ. ${ }^{42-43}$

The lamina propria surrounding the epididymal duct demonstrates a layer of elastic fibers which is very thick in winter, thick in spring and thin in other seasons. The increased thickness of the elastic fibers in winter may predispose for the increase in the total diameter of the epididymal duct in spring. The muscular coat however, shows moderate variations in thickness between different segments of the epididymal duct in different seasons of the year. Most importantly this coat is the thickest in the middle and terminal segments in spring as compared to other seasons. Thick muscular coat in the terminal segment in spring may be helpful for powerful ejaculation. ${ }^{20}$

\section{References}

1. Novoa C. Review reproduction in Camelidae. J Reprod Fertil 1970;22:3-20.

2. Schwartz H J, Dioli M. The one humped camel (Camelus dromedarius) in Eastern Africa, First edition. Weikersheim: Margraf Verlag; 1992.

3. Brown BW. A review on reproduction in South American camelids. Ani Reprod Sci 2000;58:169-95.

4. Lodge JR, Salisbury GW. Seasonal varia- 
tions and male reproductive efficiency. In: The Testis. Johnson AD, Gomes WR, Vandemark NL. eds. New York: Academic Press; 1970.

5. Abdel-Raouf M, El-Naggar MA. Studies on reproduction in camels (Camelus dromedarius): mating technique and collection of semen. J Vet Sci 1964;1:113-9.

6. Musa BE, Abusineina ME. Clinical pregnancy in the camel and a comparison with bovine pregnancy. Vet Rec 1978;102:2-10.

7. Al Eknah MM. Reproduction in Old World camels. Anim Reprod Sci 2000;60:583-92.

8. Senger PL. The organization and function of the male reproductive tract. In: Pathways to pregnanacy and parturition, second edition. Pullman: Current Connception; 2003.

9. Tingari MD, Moniem KA. On the regional histology and histochemistry of the epididymis of the camel (Camelus dromedarius). Reprod Fertil 1979;57:11-20.

10. Romeis B. Mikroskopische Technik. München, Wien, Baltimore: Urban und Schwarzenberg; 1989.

11. Harris HF. On the rapid conversion of haematoxylin into haematein in staining reactions. J App Micr Lab Meth 1900;3:777.

12. Mc Manus JFA. Histological demonstration of mucin after periodic acid. Nature 1946;158:202.

13. Steedman HF. Alcian blue 8GS: a new stain for mucin. Quart J Micr Sci 1950;91:477-9.

14. Crossmon GA. Modification of Mallory's connective tissue stain with a discussion of principles involved. Anat Rec 1937;69: 33-8.

15. Weigert C. Über eine Methode zur Färbung elastischer Fasern. Zentrablatt füer Allgemeine Pathologie und Pathologische Anatomie 1898;9:289-92.

16. Karnovsky A. A formaldehyde-glutaraldehyd fixative of high osmolarity for use in electron microscopy. J Cell Biol 1965;27: 137.

17. Mollenhauer HH. Plastic embedding mixture for use in electron microscopy. Stain Technol. 1964;39:111-4.

18. Richardson KC, Jarett L, Finke EM. Embedding in epoxy resins for ultrathin sectioning in electron microscopy. Stain Technol 1960;35:313-23.

19. Bedford JM. Effect of duct ligation on the fertilizing ability of spermatozoa in the epididymis of the rabbit. J Exp Zool 1967; 166:271-82.

20. Alkafafy M. Glycohistochemical, Immunohistochemical and Ultrastructural Studies of the bovine epididymis. Available from: http://edoc.ub.uni-muenchen.de/3153/

21. Erkmann G. Histologische und histochemische untersuchungen zur segmenteinteilung des Nebenhodens vom Rind vor und nach Geschlechtsreife. Cytobiologie 1971;3:37-69.

22. Sinowatz F. Ultrastrukturelle und enzymehistochemische untersuchungen am Ductus epididymidis des Rindes. Fortschritte der veterinärmedizin. Berlin Hamburg: 1981.

23. Goyal HO. Morphology of the bovine epididymis. Am J Anat 1985;172:155-72.

24. Axner E, Malmqvist M, Linde-Forsberg C, Rodriguez-Martinez H. Regional histology of the ductus epididymis in the domestic cat. J Reprod Dev 1999;45:151-60.

25. Crabo B. Studies on the composition of epididymal content in bulls and boars. Acta Vet Scand 1965;22:1-92.

26. Turner TT. Resorption versus secretion in the rat epididymis. J Reprod Fertil 1984; 72:509-14.

27. Johnson L, Amann RP, Pickett DW. Scanning electron microscopy of the epithelium and spermatozoa in the Equine excurrent duct system. Am J Vet Res 1978; 39:1428-34.

28. Dellmann HD, Wrobel KH. Male reproductive system. In: Dellmann, HD, Brown EM. Textbook of Veterinary Histology, second edition. Philadelphia: Lea\& Fiebiger; 1981.

29. Ross MH, Reith EJ, Romrell LJ. Histology. A Text and Atlas, second edition. Baltimore: Williams \&Wilkins; 1989.

30. Junqueira LC, Carneiro J. Basic histology: Text and Atlas. Tenth edition, Toronto, New York, London, Sydney, Melan, Newdelhy, Lisbon, Madrid: McGraw Hill; 2003.

31. Martini FH, Ober WC, Garrison CW, et al. Fundamentals of anatomy and physiology, fifth edition, Prentice Hall, upper saddle River, New Jersey. 2001.

32. Yamamoto M, Turner TT. Epididymis, sperm maturation, and capacitation. In: Infertility in male, second edition. St. Louis, Baltimore, Boston, Chicago, London, Philadelphia, Sydney, Toronto: Mosby Year book; 1991

33. Lòpez ML, Grez P, Gribbel I, Bustos-obregon E. Cytochemical and ultrastructural characteristics of the stallion epididymis (Equus Caballus). J Submicrosc Cytol Path 1989;21:103-20.

34. Bodenheimer FS. Biology of Deserts. In: Cloudsley Thompson. London: Institute of Biology; 1954.

35. Charnot Y. Sychronisms de croissance de l' expansion palatale et du testicule et course du cycle sexual du dromadaire. Bull Soc Sci Nat Phys Maroc 1963;34:1607.

36. Shalash MR. Some reproductive aspects in the female camel. Wild Rev Anim Prod 1965:1-103.

37. Osman AM, El Azab EA. Gonadal and epididymal sperm reserves in the camel, Camelus Dromedarius. J Reprod Fertil 1974;38:452-30.

38. Abdel-Raouf M, El-Bab, MR, Owaida, MM. Studies on reproduction in the camel (Camelus dromedarius) V. morphology of the testis in relation to age and season. $\mathrm{J}$ Reprod Fertil 1975;43:109-16.

39. Zayed AE, Hifny A, Abou-Elmaged A, Wrobel KH. Seasonal changes in the intertubular tissue of the camel testis (Camelus dromedarius). Ann Anat 1995;177:199212.

40. Tingari MD, Ramos AS, Gaili ESE, et al. Morphology of the testis of the onehumped camel in relation to reproductive activity. J Anat 1984;139:133-43.

41. Salisbury GW, Van Demark NL, Lodge JR. Physiology of reproduction and artificial insemination of cattle, second edition. San Francisco: W.H. Freeman and company; 1985.

42. Aguilera-MerloC, Münoz E, Dominguez S, et al. Epididymis of Viscacha (Lagostomus maximus maximus): Morphological changes during the annual reproductive cycle. Anat Rec 2005;282:83-92.

43. Aguilera-Merlo C, Fogal T, Dominguez S, et al. Ultrastructural and biochemical seasonal changes in epididymal corpus and cauda of viscacha (Lagostomus maximus maximus). J Morphol 2009;270:805-14.

44. Ramos AS, Dym M. Fine structure of the monkey epididymis. Am J Anat 1977;149: 501-32.

45. Tingari MD. The fine structure of the epithelial lining of the epididymis of the camel (Camelus dromedarius) with special reference to regional differences. J Anat 1989;165:201-14.

46. Abou Häila A, Fain-maurel MA. Regional differences of the proximal part of mouse epididymis: morphological and histochemical characterization. Anat $\operatorname{Rec} 1984 ; 209$ : 197-208.

47. Yagil R, Etzion Z. Hormonal and behavioural patterns in the male camel (Camelus dromedarius). J Reprod Fertil 1980;58: 61-5.

48. Samuelson DA. Textbook of Veterinary Histology. London: Elsevier; 2007. 